\title{
MIGRANTES NO FAXINAL E MIGRAÇÕES DE FAXINALENSES: TERRITÓRIOS E POVOS TRADICIONAIS
}

\author{
Ancelmo Schörner* \\ José Adilçon Campigoto Correio***
}

\begin{abstract}
Resumo: Este texto trata do processo migratório de faxinalenses para Irati a partir dos anos de 1980. A região dos faxinais se encontra em uma área reconhecida geograficamente como Matas das Araucárias (região dos pinheirais). Nesse caso compreende municípios localizados na região centro sul do Paraná, tais como Rebouças, Guarapuava, Irati e Ponta Grossa. Nessas florestas coexistem representantes da flora tropical e temperada do Brasil, sendo dominadas, no entanto, pelo pinheiro-do-paraná. Devido ao seu alto valor econômico, ela vem sofrendo forte pressão de desmatamento, o que contribuiu para o processo migratório. Realizamos entrevistas com ex-faxinalenses com o intuito de estudar quais as principais transformações ocorridas no faxinal a partir desse período. Além disso, traçamos, em linhas gerais, o processo de desterritorialização dessas pessoas, pois ir para a cidade é, em parte, deixar uma cultura herdada para se encontrar com outra, cuja história se desconhece, cuja memória é estranha.
\end{abstract}

Palavras-chave: Faxinal. Migração. Desterritorialização/Reterritorialização.

Abstract: This paper deals with the migration process of faxinalenses to Irati from the year 1980. The region of faxinais is in an area known geographically as the Araucaria Forest (region of pine forests). In this case comprises municipalities located in the central southern Paraná, such as Rebouças, Guarapuava, Irati and Ponta Grossa. In these forests there are representatives of tropical and temperate flora of Brazil, being dominated, however, the Paraná pine. Due to its high economic value, it has come under heavy pressure from deforestation, which contributed to the migration process.

\footnotetext{
* Professor na Universidade Estadual do Centro-Oeste - UNICENTRO.

E-mail: ancelmo.schorner@terra.com.br

** Professor na Universidade Estadual do Centro-Oeste - UNICENTRO.

E-mail: ja.cam.pi@hotmail.com
} 
We conducted interviews with former faxinalenses in order to study what are the main changes occurring in the faxinal from that period. We also outline in general terms, the process of deterritorialization of these people, because going to the city is in part a cultural legacy to leave to meet with someone whose history is unknown, whose memories are strange.

Keywords: Faxinal. Migration. Deterritorialization/Repossession.

\section{INTRODUÇÃO}

Atualmente, o empenho de cientistas pertencentes a várias áreas do conhecimento na investigação e no reconhecimento legal dos grupos marginais apresenta-se como desafio aos historiadores da cultura. Parece que, em nenhuma outra época, se falou tanto sobre o tema e se estudou tanto estes grupos classificados, ainda, como excluídos da história. ${ }^{1}$ A exclusão por meio da escrita implica marginalização social e histórica e deve-se à aplicação de esquemas teóricos gerais e globalizantes que comportam a negligência e até mesmo o menosprezo a respeito das peculiaridades, das características e das singularidades que nos permitem identificá-los como objetos de estudo. O interesse por esses grupos vincula-se ao que se tem classificado como povos tradicionais.

Sob tal categoria abriga-se a diversidade de grupos e tipos de povoamento existentes em determinado território ou país, em geral, marginalizados socialmente. No caso do Brasil abrange, por exemplo, os indígenas, os remanescentes de quilombos, os caiçaras, os babaçueiros, os caboclos, os caipiras, os sertanejos, as quebradeiras de côco, os pantaneiros, os jangadeiros, os pescadores artesanais, os seringueiros e os faxinalenses. ${ }^{2}$

Chamamos Sistema de Faxinal $^{3}$ um modo de utilização das terras em comum, existente na região Sul do Brasil, para a criação de animais e que se tem classificado como manifestação cultural pertencente à categoria dos povos tradicionais: forma própria de uso e posse da terra, o aproveitamento ecológico dos recursos naturais - pinhão, guabirobas, araçás, pitangas e jabuticabas -, o cultivo da vida comunitária e a preservação de memória comum. ${ }^{4}$ Os estudiosos do assunto apontam que o sistema faxinal constitui-se como acontecimento singular por causa de sua forma organizacional. Distingue-se tal sistema dos outros pelo uso coletivo da terra para a criação de animais. O caráter coletivo se expressa na forma de criadouro comum. ${ }^{5}$

Sobre a origem do Sistema dos Faxinais em Rebouças, ${ }^{6}$ há a tese de que ocorreu no final do século XIX, graças à economia ervateira que se desenvolveu nessa região. A exploração da erva-mate nativa atraiu gente que se estabeleceu ali, formando a comunidade. Eram migrantes ucranianos, poloneses, alemães, 
russos, italianos, espanhóis e caboclos. Esses migrantes se integraram na atividade ervateira e as terras de onde se extraía erva-mate foram cercadas e passaram a ser utilizadas para a criação de animais. ${ }^{7}$ Porém, os moradores do faxinal dos Marmeleiros afirmam que a época de sua formação data do final do século XIX e início do século XX. Para eles, o sistema teve origem com a Revolta do Contestado, pois muitas pessoas fugiram do conflito e compraram ou requisitaram a posse de terras em Rebouças e assim o sistema teria se formado. ${ }^{8}$

\section{O FAXINAL DO MARMELEIRO E SUAS TRAJETÓRIAS MIGRATÓRIAS}

As migrações não constituem uma novidade, pois os homens historicamente sempre se deslocaram. Em cada época da história, contudo, elas são distintas nas causas que motivam, nas modalidades dos deslocamentos, nas implicações, no significado que lhes atribuem e nas emoções que suscitam tanto entre aqueles de onde saem os imigrantes quanto entre aqueles que os acolhem. ${ }^{9}$

Nesse sentido, pensamos na migração como usuária e reelaboradora do espaço e do processo de espacialidade. A migração é um fenômeno que faz com que se repensem as atuais concepções sobre sedentarismo e mobilidade, pois ambas encerram a idéia mais ou menos abstrata de espaço, bem como a de esferas identitárias e zonas de produção de evidências mais ou menos compartilhadas. Falar dela - da imigração - implica levar em conta conceitos como os de territorialidade, de desterritorialização e de reterritorialização que podem envolver uma pessoa ou várias. ${ }^{10}$

Ao se analisar a migração como fenômeno histórico, social, político e econômico, a região de "origem" (neste caso o faxinal) e a região de "destino" (neste caso, Irati) não são realidades estanques e nitidamente separadas, mas sim face e contraface da mesma moeda. Há entre elas correlação de forças, onde, numa leitura economicista, pode-se dizer que a lógica do capital aprofunda o abismo existente entre eles. Então, nessa mesma perspectiva, não são propriamente as luzes da cidade que atraem os faxinalenses, mas a falta de reais condições de trabalho e de vida é que o leva a migrar. $\mathrm{O}$ objetivo deste artigo, no entanto, não é discutir as reais causas desse movimento migratório.

Pensamos o migrante não apenas quem migra, mas como sujeito vinculado ao um conjunto de unidade social de referência. O objetivo é contornar a compreensão geral oriunda de estudos demográficos e econômicos, que tratam do número de pessoas que migram, individualizam os migrantes e escamoteiam as unidades sociais efetivamente envolvidas no drama de migrar, como as famílias e as comunidades. ${ }^{11}$

A migração é um fenômeno interessante em si mesmo, sendo considerada como um importante aspecto no diagnóstico das estruturas sociais e econômicas 
das sociedades de origem e de recepção das pessoas. No afã de se tentar explicar os motivos da migração tem havido várias discussões. As classificações dos tipos de migração como expulsão-atração ou a idéia de subsistência ou melhoria de vida são formas úteis para análise, desde que nos lembremos das suas limitações conceituais. Para se ter uma melhor compreensão da construção do modo de vida que os migrantes estabelecem, é essencial sabermos as motivações e razões da opção por uma região específica. ${ }^{12}$

A migração é um processo social e seus motivos e razões, embora subjetivos em parte, correspondem a características dos indivíduos: jovens podem ser mais propensos a migrar que adultos ou idosos, alfabetizados mais que analfabetos e solteiros mais do que casados. Além disso, se a unidade migratória deixa de ser o indivíduo para ser o grupo, também deixa de ter sentido investigar a migração como um movimento de indivíduos num dado período entre dois pontos, geralmente considerados como de "origem" e de "destino". ${ }^{13}$

Os deslocamentos espaciais de indivíduos e grupos configuram-se, pois, como momentos de crise e (re)construção de identidades. A trajetória do migrante é marcada pela reelaboração de seus referenciais identificatórios (traços sócio-culturais com os quais os sujeitos identificam-se e a partir dos quais se fazem reconhecidos como membros de um grupo) e envolve o questionamento de valores e de imagens de si e do outro, ${ }^{14}$ o que produz identidades plurais, mas também identidades contestadas, em um processo que é caracterizado por grandes desigualdades..$^{15}$

Alguns estudos sobre os faxinais apontam que mudanças, especialmente culturais, tornaram-se perceptíveis no faxinal ( no caso dos Marmeleiros) com a chegada dos migrantes ditos gaúchos, ${ }^{16}$ na década de 1980 . No entanto, pode-se dizer que muitos fatores estiveram presentes, nas modificações ocorridas nos faxinais. Sobre a vinda dos dito imigrantes gaúchos, a tese é de que, na maioria, eram pequenos e médios agricultores que estavam passando por dificuldades financeiras. A política de crédito agrícola do regime militar favorecia os latifundiários e acentuava a concentração de terras em suas mãos. O crédito rural subsidiado só era acessível aos agricultores que, como garantia de empréstimo, pudessem oferecer a terra ou alguns bens - à hipoteca. ${ }^{17}$

Rupp e Martins escreveram que, na década de 1980, após o regime militar, a situação de muitos agricultores estava ruim no Rio Grande do Sul, fazendo com que muitos deixassem o Estado. Nesse contexto é que Rebouças recebeu várias famílias vindas do Rio Grande do Sul. Ao comprarem terras em comunidades de faxinais, exerceram uma forte pressão cultural que, aliada a outros fatores, desestabilizou e até acabou com o sistema em alguns lugares. ${ }^{18}$ Esse dicurso sobre a 'imigração gaúcha' é corrente, mas velado, no faxinal dos Marmeleiros. Assim, um dos depoentes que solicita anonimato afirma: 
Muita gente diz que os gaúcho não atrapalharam o faxinal. Mas eu digo que sim. Porque quando o faxinalense tem um pedaço de terra e planta no sistema dele, sem máquina, sem veneno, sem trator, essas coisa, sempre tem trabalho e tem para todo mundo. Mas quando se entra na terra com isso tudo, máquina, trator, aí o que uns fazem num tempo eles fazem em bem menos e sem precisar de gente. Então eu digo que eles atrapalharam sim. E tem outra coisa. Eles foram comprando terra e vendendo. Comprando e vendendo. Aí comprava um pedaço de um, depois de outro. O povo já estava sem recurso e acabou vendendo. Uns até que não queriam, mas acabavam vendendo porque sua terra ficava pequena, que era arendada e o dono tinha vendido. Então ele não tinha mais onde viver. Ia ficando no meio de um monte de terra grande, de fazendeiro e ele pequeno, com pouca terra. Então isso tudo fazia o povo ir embora. A maioria que eu conheço veio para Irati, que tinha mais recurso que Rebouças. ${ }^{19}$

Conforme os depoimentos, algumas pessoas do faxinal, ou moradoress próximos dele, fizeram o papel de 'atravessadores', comprando terra dos faxinalenses e vendendo para outros. S.A diz:

Eu comprei e vendi terras aqui no Marmeleiro. Até teve uma situação que eu vendi [...] umas duas ou três vezes. O gaúcho ia comprando e depois não gostava, não conseguia pagar e vendia novamente. Aí eu comprava e arrumava outro para comprar. Assim ía [....$^{20}$

A tese de que a chegada do 'colono de origem gaúcha' causou um impacto destrutivo em tremo sócio culturais, visto que os recém-chegados eram portadores de outra bagagem cultural, bem diversa daquela dos moradores dos faxinais foi defendida, também por Maria Magdalena Nerone. ${ }^{21}$

Para Rupp e Martins, os gaúchos escolheram as terras de faxinal para se estabelecerem porque, aqui, as propriedades rurais eram vendidas a um preço mais acessível do que no Rio Grande do Sul. Eram terras de solo fraco, nas quais não se utilizava calcário ou adubos químicos. Os autores afirmam que, naquele momento, haviam pessoas vendendo suas terras para morar na cidade, porque não tinham mais condições de sobrevivência no sitema faxinal, já que a política agrícola favorecia aos grandes agricultores, assim como ocorria no Rio Grande do Sul ${ }^{22}$. Segundo Enedina, 
Aqui as terras estavam se acabando. Muita gente tinha um pedaço pequeno, que não dava para o sustento e então acabava tendo que vender e ir embora era melhor, era a solução. Muitos pensavam que na cidade tinha emprego para todo mundo; estudo para os filhos também era importante e, então, iam vendendo e saíndo daqui. A maioria foi em busca de recursos em Irati. ${ }^{23}$

A palavra recurso tem, aqui, um sentido amplo e refere-se, basicamente, à existência de oportunidades de empregos. Ela também está relacionada à oferta de certos serviços públicos, como assistência médica, escolas e transportes, à pavimentação, e à existência de um comércio variado e rico. Esses benefícios, os depoentes os percebem como vantagens na cidade: possibilidade de salários elevados, de assistência médica, de instrução. Como diz o ex-faxinalense M.F.P,

É... se for comparar dá para dizer que na cidade é melhor... mas tem um preço. Aqui você tem que pagar água, luz, para pegar o lixo. Tudo tem que pagar. No mercado é tudo caro. Tem que pagar. Lá no faxinal, não. Você tinha água de graça; luz, pagava; mas era pouco. Comida, sempre tinha... que você mesmo tinha uma rocinha e uma horta. Tinha animal que matava e tinha carne... banha... tinha leite. Então, tudo tem que comparar para dizer se é melhor ou não. Mas que aqui tem vantagem? Tem. ${ }^{24}$

Para alguns depoentes, a migração é uma possibilidade de resolução dos problemas, das dificuldades cotidianas da vida no campo. E na busca desse sonho, fixaram-se na área urbana de Irati ou de Rebouças, lugares onde as condições de vida, segundo eles, são melhores do que no Faxinal. Assim, diante dos baixos rendimentos, da falta de segurança no trabalho, das intempéries e da colheita que não rendeu, a perspectiva de superar sua condição consiste em conseguir um emprego urbano. Nesse sentido, a migração para a cidade pode ser considerada como mais vantajosa, pois o trabalhador encontra instituições que podem orientar o processo de sua ressocialização. Mesmo quando ele não se integra efetivamente nessas instituições (sindicatos, organizações assistenciais), dela se beneficia indiretamente através das reivindicações de classe, o que favorece seu ajustamento, melhorando suas condições de vida e abrindo novas possibilidades de ascensão para as gerações subseqüentes. ${ }^{25}$

No faxinal, na década de 1980, os migrantes vindos do sul passaram a ser vistos por alguns faxinalenses como latifundiários, estranhos ao sistema. Afirma-se que o primeiro problema que surgiu entre eles diz respeito às cercas, pois a "cerca coletiva é vital para a manutenção do Sistema de Faxinal, pois 
o cercamento individual supõe a morte do Sistema, pois secciona um espaço que a princípio é de uso comum. ${ }^{26}$

Nerone argumenta que a cerca passou a ser o centro dos conflitos, porque "na ótica do recém-chegado, ela representava um obstáculo ao progresso e era necessário romper a qualquer custo com essa tradição." ${ }^{27}$ É discurso corrente que a disputa em torno das cercas desarticulou vários faxinais no município, muito embora isso não tenha acontecido com o faxinal dos Marmeleiros.

Ainda em relação à disputa em torno das cercas, frisa-se que, em muitos casos, a sua não conservação pelos faxinalenses também contribuía para que os animais entrassem nas terras dos novos moradores dos faxinais, o que causava e tem causado uma série de problemas, tais como a morte, o envenenamento e a tortura das criações. Nerone afirma que muitos dos novos proprietários, quando a questão ia parar na justiça, acabavam ganhando a causa, pautados que estavam na Lei Federal dos Quatro Fios.

Um dos argumentos jurídicos utilizados contra o criadouro comum é a 'Lei Federal dos 4 Quatros Fios' do Código Brasileiro, a qual foi criada em 1916. Porém a lei somente começou a ser posta em prática de fato há aproximadamente doze anos. Esta lei estabelece claramente que as criações é que devem ser cercadas e não as plantações. [...] Ela estabelece que o proprietário tenha suas terras cercadas com quatro fios de arame, o animal que nela penetrar será considerado invasor e, portanto, a Lei permite que o proprietário apreenda o animal. ${ }^{28}$

Conforme os próprios depoentes, antes mesmo da vinda dos migrantes sulinos já existiam problemas com as cercas do criadouro - os animais, às vezes, invadiam as plantações, o que gerava discussões entre os vizinhos. Afirmam, no entanto, que antes esses problemas eram resolvidos rapidamente entre os próprios vizinhos e não chegavam a ser um obstáculo para o "bom funcionamento" do sistema. José Cordeiro Amaral e João Santos dizem que, em geral, a vida era tranquila nos faxinais. Ou seja, tinham uma vida sem grandes problemas dentro do sistema, apenas pequenos conflitos que eram resolvidos rapidamente. Por outro lado, isso significa também que o nível de vida dos faxinalenses era satisfatório, pois dispunham de alimentos e bens materiais que consideravam suficientes para viverem bem. ${ }^{29}$

Júlio Andrade diz que as pessoas viviam basicamente da criação de animais, destacando-se os porcos, cabritos, eqüinos e aves, além do gado bovino, criado em menor escala. Nas plantações cultivavam-se milho, feijão, arroz, frutas e verduras, para subsistência. Somente o excedente era comercializado. 
Não havia uma agricultura mecanizada, sendo o trabalho realizado com a tração animal e, também, manualmente. Aravam e capinavam as roças, sem utilizar fertilizantes e agrotóxicos, como na atualidade.

No faxinal eu trabalhava em terra dos outro. De empreitada. Terra mesmo só onde nós morávamos, que era tipo herança da mulher. Mas do resto era na terra dos outros. Mas lá a gente plantava de tudo um pouco para viver. Mas era com enxada, arado e cavalo onde a terra deixava, era na enxada, foice, machado. Não tinha máquina, essa 'coisarada' de máquina, de trator, de veneno que tem hoje. Não tinha nada. Então tinha lugar para trabaiar. Com máquina não tem. Veja, se eu fazia uma roça do nosso jeito e levava, digamos, dois meses, com trator era dois dias e não precisava de quase ninguém pra trabalhar. E o povo ia viver como? Tinha que ir embora. [...]. Lá se criava todo tipo de bicho, sempre solto. Eu cheguei a ter uns 400 porco. E tudo rendia para o pessoal. Por exemplo se você precisava de alguma coisa de dinheiro era pegar uns porco e vender. Eu até brinco que o nosso dinheiro andava solto, que era os porcos. Quer dizer, o dinheiro tava ali andando, 'fuçando'. Se precisasse era só pegar e vender que se fazia dinheiro. ${ }^{30}$

Rupp e Martins afirmam que, quando os gaúchos chegaram e quiseram utilizar a terra de uso comum para a prática agrícola, na maior parte dos casos, a população local tentou impedi-los e levaram o caso à justiça. Os recémchegados, por sua vez, obtinham o respaldo da lei e, geralmente, ganhavam a causa. Os autores argumentam que com os migrantes chegaram as máquinas. Foram trazidos tratores, grades, arados, semeadeiras, colhedeiras e outros implementos. Com isso, as grandes lavouras foram tomando o espaço dos pastos de "uso comum". Isso acabou gerando mudanças, também no modo de agir de alguns faxinalenses.

[...] daí as própria pessoa que as vezes tinha área a par de onde vem muita imigração, sem poder criar ele tornou-se a fazê a mesma coisa. Porque daí ele não podia criar, daí ele começou a fazer lavoura também, né? nos faxinais, porque daí ele tem que prender as criações para não causar conflito, porque é por ali que foi a emenda que acabou destruindo vários faxinais. ${ }^{31}$

A partir dos depoimentos, porém, nota-se que nem todos o faxinalenses aderiram a esse modelo de cultivo, até mesmo porque muitos dos moradores 
do faxinal nem possuíam terra, apenas usufruíam as terras de uso comum. Houveram, também, vários casos de moradores possuidores de terras que mantiveram a antiga forma de organização e uso da terra. Continuaram plantando da maneira como estavam habituados. Algumas pessoas que não possuíam terras, como é o caso de um de nossos depoentes, migraram para as cidades devido à diminuição das àreas comuns e, fatalmente, naqueles casos em que o sitema deixou de ser usado. Sem experiência para profissões urbanas, muitos precisaram enfrentar dificuldades nas periferias de pequenas e médias cidades da região. Enedina da Rosa narrou a seguinte história:

Meu marido veio primeiro, para arrumar casa. Isso foi em 1985, em agosto. A gente até tinha condição, mesmo que a terra era alugada. Mas aí ele ficou doente e eu sozinha não conseguia mais tocar a roça, fixar no faxinal. Mas teve também o caso de que as terras, que eram alugadas, foram sendo vendidas, os gaúchos iam comprando do povo de lá e espremendo todo mundo e quem não tinha condição de se segurar, acabava indo embora. A gente via isso, que se não fosse pela doença mais dia menos dia tinha que acabar saíndo também. Mas não que fosse tão necessário por causa da compra de terras pelos gaúchos. Mas teve muita gente que veio para Irati, que a maioria que conheço, e conheço bastante, veio foi pra Irati e não para Rebouças, por causa das venda de terra. $O$ povo não agüentava e tinha que ir embora. Não tinha máquina, não tinha dinheiro como eles e não se sustentava mais porque eles compravam as terras e iam dando um jeito do povo sair de lá ir para cidade onde a vida não era fácil. Muitos que conheço chegaram a penar muito, com falta de emprego e tudo. ${ }^{32}$

O depoimento de Enedina aponta para outras causas da imigração. Causas cotidianas tais como a doença do marido, a falta de ânimo para empreender atividade sozinha, a fata de dinheiro e a falta de apoio. No discurso acadêmico, geralmente se dirá, entre outras coisas, que o uso de máquinas na lavoura tornou dispensável a presença do agregado, trabalhador dos ervais que havia se adequado a um novo trabalho, o das lavouras, principalmente de feijão. Entretanto, a partir dos anos de 1970, os tratores, as colheitadeiras, os caminhões, passaram a fazer parte desse cenário. Ilma Aparecida, também exmoradora do faxinal, diz que os agregados, aos poucos, foram sendo expulsos para a cidade, mas houve gente que migrou para outras localidades em que ainda mantinham o sistema. ${ }^{33}$

Para muitos faxinalenses, conforme se depreende dos depoimentos, não há "progresso" na agricultura mecanizada, porque vêem-se diante de muitos 
problemas: afirmam que a vida deixou de ser tranqüila! Podemos dizer que a agricultura mecanizada é elitizada e, por isso, estranha aos faxinais. É manejo adequado às grandes propriedades, fugindo às características dos faxinais, nos quais predominam as pequenas propriedades, baseadas na agricultura de subsistência, na mão-de-obra familiar e no uso comum dos recursos naturais tais como as aguadas, a lenha, os frutos silvestres e as pastagens do criatório comum.

Alguns faxinalenses releem a história recente dos faxinais incorporando a tese de que a mecanização, trazida pelos gaúchos, trouxe também novas culturas. A principal foi a soja, segundo José Cordeiro - morador do Marmeleiro de Baixo. O discurso também ecoa nos textos acadêmicos. Afirma-se que a soja não era cultivada nessa região, mas, a partir da vinda dos migrantes, seu cultivo se deu em grande escala, sendo, hoje, um dos produtos mais cultivados ${ }^{34}$. Mas pode-se notar certas contradições.

Fernando Andrade, entrevistado por Marla Rupp, diz que a soja já era cultivada na região quando chegaram os migrantes e que eles não causaram mudanças no sistema, mas que as mudanças foram causadas pelos próprios moradores do local. Andrade argumenta que os moradores do faxinal seriam os responsáveis pelos problemas do faxinal, pelos cercamentos individuais e que não estariam cuidando da manutenção das cercas coletivas. As cercas individuais existiam dentro dos faxinais antes da chegada dos gaúchos, diz o morador do Marmeleiro de Baixo. A dita 'chegada dos gaúchos'é, sem dúvida um marco na memória e na história dos faxinais, particularmente, no município de Rebouças. Mas a interpretação que se faz desse marco é variável.

Alguns depoentes afirmam que, com a vinda dos migrantes, houve um considerável impacto sobre o manejo e a criação de animais. Na medida em que aumentou a área das terras utilizadas para as plantações, houve necessidade de se diminuir o número de animais.

O manejo com os animais, ele mudou. Num Sistema que o primeiro faxinal era um faxinal bem grande. Daí, com a entrada, com a imigração, ele começou a individualizar um pouco os faxinais. O pessoal comprava uma área de terra, ali destocava, tinha que fechar, né? Então os faxinais começou a ficar cada vez mais pequeno. Que o nosso faxinal aqui, ele emendava com Saltinho, Rebouças, Rio Azul e ia até São Mateus, a comunidade que entrava a imigração já acabou, acabou dispersando o faxinal tinha que fazer uma cerca, dividir. ${ }^{35}$

Na maior parte das vezes, esses novos produtores desejavam transformar suas terras, que faziam parte do criadouro, em terras de plantação, já que os 
insumos modernos lhes permitem plantar uma área maior de terra com o mesmo dispêndio de trabalho. Conforme E.S.P

A técnica com que se planta ajuda quem produzir em grande quantidade. Isso os faxinalense não tinham condição de fazer. Os preços dos nosso produtos iam baixando, baixando... a margem de lucro, que significa sobrevivência. Mas se não tem condições de produzir, se se é agregado, tem terra alugada e tem uma situação assim, o pessoal acaba vendendo o que tem e vai embora para cidade. ${ }^{36}$

A maioria dos migrantes também possuía animais, o gado leiteiro principalmente. A principal diferença, contudo, estava no manejo com os mesmos. No primeiro casos eles não são criados no criadouro, mas fechados em pastagens de uso não coletivo. Amador Ferreira diz que no criadouro comum, no sistema de faxinal

Tudo criava. As frutas eram em abessas, né? Tinha bastantes árvores de guabirobas, e outras frutas. Tudo o que era fruta tinha. Agora não tem mais [...] Raiz, taquara, aqui tinha até taquarazão. As vacas viviam gordas, bonitas, sem remédio [...] sem nada. Agora o bicho é abaixo de remédio e não cria mais [...] Hoje a fraqueza, a fraqueza do gado, da criação, que fazem esses problemas e que daí as doenças atacam $[\ldots]]^{37}$

Para E.S.P, as modificações ocorridas na história recente dos territórios faxinalenses atinge até os animais. Diz ele que

Para os animal também tem mudança. Que os animais são, vamos falar assim, o centro do faxinal. Que sem animal não se tem faxinal. Mas tem que ser bicho solto. Aí a plantação de soja que é feita em quantidade boa acaba trazendo essa mudança, que os bicho não tem mais lugar onde andar, onde se criar solto. O povo acaba vendendo, deixando de criar para não dar poblema com os vizinhos, que tem terra boa, grande. ${ }^{38}$

A idéia de que a diminuição da área do criadouro impossibilita a criação às soltas parece estranha àqueles que não conhecem o território dos faxinais. Ali, criar solto significa criar dentro do território destinado à criação. 


\section{TERRITÓRIO, MIGRAÇÃO E DESTERRITORIALIZAÇÃo}

Território é uma palavra que deriva do latim 'terra' e 'torium', significando terra pertencente a alguém. Pertencente, entretanto, não se vincula, necessariamente, à propriedade da terra, mas a sua apropriação ${ }^{39}$. O território é, então, o espaço territorializado, apropriado. É lugar de relações sociedadenatureza e homens-homens; em função disso, espaço de ação e de poder. A passagem do espaço ao território ocorre quando este é balizado, modificado, transformado por redes e fluxos que aí se instalam. ${ }^{40}$

A noção de território aqui é entendida num sentido muito amplo. Os seres existentes se organizam segundo territórios que os delimitam e os articulam aos outros existentes e aos fluxos cósmicos. O território pode ser relativo tanto a um espaço vivido, quanto a um sistema percebido no seio da qual um sujeito se sente "em casa". O território é sinônimo de apropriação, de subjetivação fechada sobre si mesma. Ele é o conjunto de projetos e representações nos quais vai desembocar, pragmaticamente, toda uma série de comportamentos, de investimentos, nos tempos e nos espaços sociais, culturais, estéticos, cognitivos. ${ }^{41}$

Isso nos permite sustentar a tese de que o território não é apenas o conjunto dos sistemas naturais e de sistemas de coisas superpostas. Assim, a idéia de território não se restringe apenas àquela da escala nacional, associada com o Estado enquanto instância gestora. Territórios existem e podem ser construídos e desconstruídos nas mais diversas escalas, tanto espaciais como temporais, e podemos identificá-lo a uma dada rua, a uma dada configuração regional, a partir de um dado recorte temporal, ou da concepção oriunda de um povo tradicional como os faxinalenses.

Esse sentido relacional presente na definição do território traduz a incorporação, simultânea, do conjunto das relações sociais e de poder, e da relação complexa entre processos sociais e espaço geográfico, concebido como ambiente natural e ambiente socialmente produzido. Além disso, esse sentido relacional implica que consideremos o significado do território não apenas vinculado às idéias de enraizamento, estabilidade, limite, fronteira, fixidez, mas também às imagens de movimento, de fluidez e de conexão. ${ }^{42}$

Território não é, então, concebido somente como suporte material, mas também como expressão e suporte de práticas e representações culturais. A circulação em redes mobiliza e altera os territórios onde tem seus pontos de referência e conexão, ao possibilitar uma ação não só contígua, mas, sobretudo, uma ação à distância. Ademais, território é, ainda, apropriação e, 
portanto, falar de territórios faxinalenses significa contar a história complexa de sua apropriação. A consciência de estar em/ser um grupo, que porta uma identidade coletiva, como a faxinalense é marcada por referências espaciais/ temporais. "[...]. Assim, o território carrega uma dupla dimensão: os atributos espaciais - contigüidade e dispersão; e os atributos simbólicos - memória e identidade coletiva." ${ }^{43}$

A vinda de um migrante para a cidade corresponde a uma mudança fundamental no tipo de relações sociais e empregatícias, e, portanto, a passagem de um sistema sócio-econômico para outro, para o qual, geralmente, ele não está preparado. É verdade que a natureza da atividade, o trabalho de campo, pode permanecer a mesma num caso, e se alterar profundamente em outro, mas não é lógico desprezar as transformações que decorrem dessa mudança de tipo de atividade. Exemplo disso pode ser o de um migrante que passa a exercer a atividade de jardineiro. Ele, mesmo tendo sido trabalhador rural, precisa passar por um processo de readequação de suas habilidades, adquirir visões sobre estética e técnicas. Ele não estará reproduzindo o trabalho que fazia anteriormente. De participante em um trabalho familiar, realizado nas roças de subsistência das pequenas propriedades ou nas tarefas das fazendas, esse migrante precisou urbanizar-se.

Para as mulheres também ocorrem mudanças. Quando se transformam em empregadas domésticas, por exemplo, têm que incorporar novos padrões, de modo especial quando trabalham para famílias de classe média ou alta. Mas assim mesmo têm como base a experiência acumulada no passado, que é aprimorada e acertada em função de certas exigências urbanas e de classe. Há, portanto, a necessidade de aprofundar um processo geral de socialização ligado de modo particular à roupa, à limpeza, à cozinha e à sociabilidade, a fim de "urbanizar" a indumentária, o paladar, os padrões de higiene e as formas de conduta $^{44}$. A ex-faxinalense Enedina diz o seguinte:

Quando eu cheguei, eu fui trabalhar na prefeitura. Mas era assim: a gente sempre tinha que se ajeitar que era para o serviço ficar certo. A gente tinha que dar uns pulos para poder ir vivendo, que se não apertar. A cidade exige muita coisa: estudo, jeito. Por exemplo: quando fui ser merendeira. $\mathrm{Eu}$ sabia que fazer comida. Mas lá era de outro tipo; era outra coisa. Tinha que saber fazer. Era bem diferente que no faxinal. Aqui tem que saber o jeito de falar, de andar, de se vestir de se comportar. Muda tudo. ${ }^{45}$

$\mathrm{Na}$ cidade exige-se também um esforço pessoal de treinamento e aprendizado que possibilite a adaptação dos indivíduos ao novo meio social. 
Podemos dizer que a duração desse período, que pressupõe a aquisição de nova identidade e prerrogativas no meio citadino, é variável, pois depende de um conjunto de fatores, como escolaridade, experiência em determinado trabalho, o que faltava aos faxinalenses.

Eu não estudei. Nunca trabalhei em nada que não fosse roça. Sei assinar o nome e nada mais. Nadinha. Então por aí já se vê que o cara que sai da roça para a cidade vai enfrentar. Se vai na fábrica diz que tem que sabe fazer tal e tal coisa. No comércio nem pegava a 'piazada' porque não sabia nada. Aí sobrava ir trabalhar na prefeitura varrendo rua, cortando mato, fazendo bico de pedreiro. Depois dum tempo a gente já sabe alguma coisa, mas ainda é pouco. A 'piazada' é que leva vantagem, que vai na escola, tem como correr atrás e se virar. Vai aprendendo e pode arrumar emprego. Mas os velho não tem jeito. É no cabo da enxada, é serviço bruto. ${ }^{46}$

Com base nos depoimentos nota-se que outro elemento que muda de significado é o trabalho. Enquanto na roça existia uma interdependência entre a atividade produtiva e os fenômenos da natureza, na cidade rompe-se inteiramente esse tipo de relação: o migrante passa a manipular, por exemplo, certos elementos culturais desvinculados da sucessão temporal de dias e noites. Alguns deles, tempos depois de chegar em Irati, quando conseguem algum emprego em fábrica, precisam inverter o horário da atividade produtiva, trabalhando de noite e descansando de dia.

Contudo, a mudança para o urbano tem, para muitos, ainda um significado de progresso.

Bem [...] eu vim para Irati por causa de uma doença. Mas lá no faxinal eu tinha alguma coisa para sobreviver. Mas a coisa é a seguinte: a gente sempre tem que botar na ponta do lápis as condição de vida. Ta certo que lá eu tinha umas coisas, mas aqui tem mais. Aqui na cidade tem recurso, tem escola para os filhos, tem médico perto se precisar, tem ônibus. Quando eu vim, em 85, fiquei uns tempos morando na casa de um tio e depois a gente foi contemplado com essa casa. Aí, agente ia pagando uma parte por mês. Depois deu certo da família conseguir um dinheiro e a gente pagou tudo, hoje a casa é nossa. Se tava lá quem sabe ainda tava morando no que não era meu. Aqui não. Então a gente tem que contar isso. ${ }^{47}$ 
A ida para a cidade, nesse caso, é lida como a causa de uma melhora de vida. Podemos pressupor que, embora ocorra uma reação de acanhamento no primeiro contato com a cidade, cujos tempos imperativos são outros, os faxinalenses decodificam e (re)elaboram essas circunstâncias impostas numa atitude que intercala fascínio e contrariedade, conformismo e resistência.

Então, pode-se dizer que a migração, em certos casos, equivale a uma nova socialização, pois a transferência para a cidade (na migração rural-urbana) - mesmo quando não implica na reformulação global de identidades - exige a aquisição de novos conhecimentos. Torna imprescindível a participação num processo produtivo, organizado em moldes diversos ao do meio rural, a reformulação de padrões de conduta, assim como o reescalonamento de valores relacionados a diferentes áreas de interação social. O migrante precisa urbanizar seus conhecimentos, interiorizando, entre outros, regras e valores de "distância" e "proximidade" social, fruto das relações interclasse imperantes na cidade. ${ }^{48}$

A cultura originária do migrante precisa ser readaptada à cidade, à fábrica, pois ele vai perdendo suas propriedades cognitivas originais com o passar do tempo. E, mesmo que não as perdesse, de pouco adiantariam na nova configuração social. Da mesma forma, precisa desenvolver sua sagacidade e astúcia pessoal a fim de obter uma parcela do excedente. Além disso, e talvez o que é pior, precisa aprender a conviver com o preconceito, a discriminação e acusações as mais diversas. A chegada pode ser um momento de estranheza e sofrimento, mas que precisou ser enfrentada. O depoimento de Enedina ilustra esta situação vivida no novo território: a área urbana.

Aqui no começo eu sofri demais com o pessoal daqui. Era muito diferente da gente lá da roça. Até parecia que não gostavam da gente, sei lá. Lembro que eles falavam que a gente era os 'tongo dos matão', os ignorantes da roça. Era assim que eles falavam para gente. E isso dava uma revolta, uma vontade de voltar, de ir embora. Mas a gente tinha que ficar que a terra lá já tinha acabado. Pouca condição de viver e então tinha que acabar ficando na cidade. Mas era doído escutar isso, que você era um 'tongo', um 'burro'. Acho que era o que eles queriam dizer da gente. ${ }^{49}$

Em quase todos os casos, os faxinalenses chegam à cidade, por assim dizer, com as raízes partidas, nos remetendo a uma referencialidade de espaço perdida, pois, o ato de saída da terra natal, em si mesmo, produz desenraizamento.

Ao perder as referências, obriga-se a encontrar formas que lhe dêem o direito de pertencer a um grupo, para dar sentido à vida. $\mathrm{O}$ desaparecimento do antigo modo de vida lhe causa muito sofrimento. ${ }^{50} \mathrm{~A}$ solidão, o medo de 
andar nas ruas, de perder-se, de ser enganado, de ser roubado o acompanha; uma angústia permanente para quem não estava acostumado com a cidade. A mesma depoente diz que

No começo eu tinha medo, medo de tudo. Até de ir para rua eu tinha medo. Lembro quando fui fazer a inscrição para trabalhar na prefeitura e que não tinha nem vestido direito para ir. Uma vizinha minha me emprestou. Aí eu fui com ela, que se ela não fosse junto acho que não tinha ido de medo. É que aqui é tudo diferente. Nos primeiros dias que a gente leva tempo para se acostumar. Mas tem que se acostumar. Aí nessas horas dá vontade de largar tudo e ir embora, voltar. Mas tem coisa que não se pode mais fazer e voltar não dava, não tinha mais terra, mais condição de viver lá e aqui já estava se estabelecendo. ${ }^{51}$

Nas narrativas da vinda para a área urbana de Irati, em que as dificuldades passadas pelas famílias são enfatizadas, a roça, o interior, o faxinal, é apresentado, geralmente, como um lugar inferior em termos de sobrevivência. Nesses termos, a cidade representa a solução para a crise pela qual passavam. A probabilidade de se conseguir emprego, em tese pelo menos, de receber salário regularmente, de ter acesso ao sistema de saúde - ainda que precário - de morar mais perto da escola, são sempre mencionados como elementos favoráveis e valorizados na mudança.

A saída do local de origem é, para a maioria dos depoentes, uma transformação radical e, podemos dizer que, em nenhum momento, essa transformação se apresenta de modo tão dramático ou tão completo como quando ocorre a transferência de indivíduos e grupos das comunidades tradicionais para os centros urbanos. Essa hipótese, que emerge dessa investigação, parte do ponto de vista de que o migrante vive e realiza, de modo concentrado, modificações nos padrões de comportamento e nas relações sociais que refletem, ao nível da ação concreta dos sujeitos, as alterações que ocorrem na ordem estrutural de uma determinada sociedade ${ }^{52}$.

Nessa mudança, o migrante "perde" aquilo que era de posse e uso comum e também o particular: a paisagem natal, a roça, as águas, as matas, a caça, a lenha, a casa, os vizinhos, as festas, a sua maneira de vestir, o entoado nativo de falar, o jeito de viver. Suas múltiplas raízes se partem. Na cidade, a sua fala é chamada de "código restrito" pelos lingüistas; seu jeito de viver, "carência cultural"; sua religião, "crendice ou folclore." 53

É esse ambiente de movimentação constante que origina a desterritorialzação, que deve ser tratada, sobretudo, no que se refere à dimensão espacial de uma sociedade que corresponde à "luta dos homens contra a 
distância"; distância que, ao mesmo tempo em que separa as sociedades, é um princípio de organização de sua vida interior. ${ }^{54}$

Entretanto, se ampliarmos essa definição, incorporando à dimensão espacial uma apropriação simbólico-cultural, veremos que a desterritorialização pode ser vista como desenraizamento no sentido de uma destruição física de fronteiras e um aumento da mobilidade, onde os indivíduos perdem seus laços com o território e passam a viver numa mobilidade e insegurança atrozes, o que leva à exploração, desintegração e instabilidade. ${ }^{55}$

Assim, desterritorialização é um termo utilizado não para o simples aumento da mobilidade, mas para a precarização territorial dos grupos subalternos, aqueles que vivenciam efetivamente (ao contrário dos grupos hegemônicos) uma perda de controle físico e de referências simbólicas sobre e a partir de seus territórios. Já que todo indivíduo não pode viver sem território, por mais precário e temporário que ele seja, desterritorialização pode se confundir, neste caso, com precarização territorial. ${ }^{56}$ Assim, haveria num sentido genérico de desterritorialização a destruição ou transformação de territórios (enquanto espaços ao mesmo tempo de dominação político-econômica e de apropriação simbólico-cultural), e num sentido mais estrito, a precarização territorial daqueles que perdem substancialmente os seus "controles" e/ou identidades territoriais, como no caso dos faxinalenses que migraram para a área urbana de Irati.

\section{NOTAS}

CAMPIGOTO, José Adilçon. Os Faxinais na Região de Irati: história e cultura. Mimeo, s/e., 2007. p. 1 .

2 CAMPIGOTO, José Adilçon. Os Faxinais na Região de Irati: história e cultura. Mimeo, s/e., 2007. p. I.

3 Sobre a origem dos faxinais: BONA, Aldo Nelson; CAMPIGOTO, José Adilçon. A hermenêutica e a origem dos faxinais. Revista de História Regional I4 (2): I27-I53, Inverno, 2009.

${ }^{4}$ CAMPIGOTO, José Adilçon. Representações sobre cultura na Região de Irati. Mimeo, s/e., 2008. p. I.

5 NERONE, Maria M. Terras de plantar, terras de criar - Sistema Faxinal: Rebouças ( 1950- 1997). 2000. Tese (Doutorado em História) - Departamento de História, Universidade Estadual Paulista, Assis.

6 O município de Rebouças, distante 156 km da capital do Estado, Curitiba, era formado por um extenso Sistema de Faxinal, mas atualmente possui apenas quatro comunidades que assim se organizam: Marmeleiro de Baixo, Marmeleiro de Cima (ambas denominadas também de Faxinal dos Marmeleiros), Barro Branco e Salto. Suas vinte e três comunidades eram faxinais, como: Faxinal dos Francos, Poço Bonito, Saltinho, Conceição, Barra dos Andrades e Rodeio (RUPP, Marla Luciana Treichel e MARTINS, Valter. Mudanças culturais nos Faxinais. In: SOCHODOLAK, 
Migrantes no faxinal e migrações de faxinalenses: territórios e povos tradicionais

Hélio; CAMPIGOTO, José Adilçon. (Org.). Estudos em História Cultural na Região Sul do Paraná. Guarapuava: Unicentro, 2008. p. 79-1 I5).

7 ALBUQUERQUE, Jey Marinho de. Importância ecológica, sócio-cultural e histórica do Sistema de Faxinal no município de Rebouças, como meio de produção auto-sustentada., 2000. Trabalho de Conclusão de Curso (Engenharia Ambiental) - Departamamento de Engenharia Ambiental, Universidade Estadual do Centro Oeste, Irati.

${ }^{8}$ RUPP, Marla Luciana Treichel; MARTINS, Valter. Mudanças culturais nos Faxinais. In: SOCHODOLAK, Hélio e CAMPIGOTO, José Adilçon. (Org.). Estudos em História Cultural na Região Sul do Paraná. Guarapuava: Unicentro, 2008. p. 79-II5.

9 ALMEIDA, Maria Geralda de. Diáspora: viver entre-territórios e entre-culturas. In: SAQUET, Marcos Aurelio e SPOSITO, Eliseu Savério. (Org.). Territórios e territorialidades: teorias, processos e conflitos. São Paulo: Expressão Popular, 2009. p. 175-195.

${ }^{10}$ ALMEIDA, Maria Geralda de. Diáspora: viver entre-territórios e entre-culturas. In: SAQUET, Marcos Aurelio e SPOSITO, Eliseu Savério. (Org.). Territórios e territorialidades: teorias, processos e conflitos. São Paulo: Expressão Popular, 2009. p. 175-195.

" MARTINS, José de Souza. A sociedade vista do abismo: novos estudos sobre exclusão, pobreza e classes sociais. 2. ed. Petrópolis: Vozes, 2003, p. 142.

${ }^{12}$ NODARI, Eunice Sueli. Persuadir para migrar: a atuação das companhias colonizadoras. Esboços, Florianópolis, n. 10, 2002, p. 29.

${ }^{13}$ NODARI, Eunice Sueli. Persuadir para migrar: a atuação das companhias colonizadoras. Esboços, Florianópolis, n. 10, 2002, p. 30.

${ }^{14}$ SOBRAL, Germano Lestenes Alves. Imagens do migrante nordestino em São Paulo. Travessia, São Paulo, n. 17, set./dez./1993, p. 19.

${ }^{15}$ WOODWARD, Kathryn. Identidade e diferença: uma introdução teórica e conceitual. In: SILVA, Tomaz Tadeu da (org.). Identidade e diferença: a perspectiva dos Estudos Culturais. Petrópolis: Vozes, 2000. P. 7-103.

${ }^{16}$ Observamos, porém, que a palavra gaúcho acabou sendo generalizada e passou a indicar todos aqueles que não eram faxinalenses, mas que de um forma ou de outra compraram terras no Faxinal, como foi o caso dos "polacos de Irati".

${ }_{17}$ RUPP, Marla Luciana Treichel; MARTINS, Valter. Mudanças culturais nos Faxinais. In: SOCHODOLAK, Hélio e CAMPIGOTO, José Adilçon. (Org.). Estudos em História Cultural na Região Sul do Paraná. Guarapuava: Unicentro, 2008. p. 79-II 5.

${ }^{18}$ RUPP, Marla Luciana Treichel; MARTINS, Valter. Mudanças culturais nos Faxinais. In: SOCHODOLAK, Hélio e CAMPIGOTO, José Adilçon. (Org.). Estudos em História Cultural na Região Sul do Paraná. Guarapuava: Unicentro, 2008. p. 79-1I5.

19 M. F. P. Entrevista concedida a Ancelmo Schörner em 22 de setembro de 2009. Das seis entrevistas realizadas, quatro não concordaram em gravá-las e pediram que seu nome fosse substituído por uma sigla ou nome fictício. Assim, colocaremos apenas as siglas após as os depoimentos. As informações completas sobre os entrevistados estão abaixo, no item fontes orais. Agradeço a llma Aparecida Toledo pela ajuda na localização de algumas pessoas, notadamente no início da pesquisa.

${ }^{20}$ S. A. Entrevista concedida a Ancelmo Schörner em 18 de junho de 2009.

${ }^{21}$ NERONE, Maria M. Terras de plantar, terras de criar - Sistema Faxinal: Rebouças (1950-1997). 
Migrantes no faxinal e migrações de faxinalenses: territórios e povos tradicionais

Tese (Doutorado em História) - Departamento de História da Universidade Estadual Paulista, Assis, 2000.

${ }^{22}$ RUPP, Marla Luciana Treichel e MARTINS, Valter. Mudanças culturais nos Faxinais. In: SOCHODOLAK, Hélio e CAMPIGOTO, José Adilçon. (Org.). Estudos em História Cultural na Região Sul do Paraná. Guarapuava: Unicentro, 2008. p. 79-II 5.

${ }^{23}$ Enedina Rosa. Entrevista concedida a Ancelmo Schörner em 16 de setembro de 2009.

${ }^{24}$ M. F. P. Entrevista concedida a Ancelmo Schörner em 22 de setembro de 2009.

${ }^{25}$ SCHÖRNER, Ancelmo. A Pedra, o Migrante e o Morro: feridas narcísicas no coração de Jaraguá do Sul/SC - 1980/2000. Tese (Doutorado em História). Programa de Pós-Graduação em História da Universidade Federal de Santa Catarina, Florianópolis, 2006. p. 82.

${ }^{26}$ NERONE, Maria M. Terras de plantar, terras de criar - Sistema Faxinal: Rebouças ( 1950- 1997). Tese (Doutorado em História) - Departamento de História da Universidade Estadual Paulista. Assis, 2000.

${ }^{27}$ NERONE, Maria M. Terras de plantar, terras de criar - Sistema Faxinal: Rebouças ( 1950- 1997). Tese (Doutorado em História) - Departamento de História da Universidade Estadual Paulista, Assis, 2000.

${ }^{28}$ NERONE, Maria M. Terras de plantar, terras de criar - Sistema Faxinal: Rebouças ( 950 - 1997). Tese (Doutorado em História) - Departamento de História da Universidade Estadual Paulista, Assis, 2000. p. 101.

${ }^{29}$ RUPP, Marla Luciana Treichel e MARTINS, Valter. Mudanças culturais nos Faxinais. In: SOCHODOLAK, Hélio e CAMPIGOTO, José Adilçon. (Org.). Estudos em História Cultural na Região Sul do Paraná. Guarapuava: Unicentro, 2008. p. 79-।I5.

30 Júlio Andrade. Entrevista concedida a Ancelmo Schörner em 16 de setembro de 2009.

${ }^{31}$ RUPP, Marla Luciana Treichel; MARTINS, Valter. Mudanças culturais nos Faxinais. In: SOCHODOLAK, Hélio e CAMPIGOTO, José Adilçon. (Org.). Estudos em História Cultural na Região Sul do Paraná. Guarapuava: Unicentro, 2008. p. 79-II 5.

32 Enedina Rosa. Entrevista concedida a Ancelmo Schörner em 16 de setembro de 2009.

33 TOLEDO, IIma Aparecida. Representações e práticas culturais no Sistema Faxinal. In: SOCHODOLAK, Hélio e CAMPIGOTO, José Adilçon. (Org.). Estudos em História Cultural na Região Sul do Paraná. Guarapuava: Unicentro, 2008. p. 1 17-150.

${ }^{34}$ RUPP, Marla Luciana Treichel; MARTINS, Valter. Mudanças culturais nos Faxinais. In: SOCHODOLAK, Hélio e CAMPIGOTO, José Adilçon. (Org.) Estudos em História Cultural na Região Sul do Paraná. Guarapuava: Unicentro, 2008. p. 79-I I5.

${ }^{35}$ RUPP, Marla Luciana Treichel; MARTINS, Valter. Mudanças culturais nos Faxinais. In: SOCHODOLAK, Hélio e CAMPIGOTO, José Adilçon. (Org.) Estudos em História Cultural na Região Sul do Paraná. Guarapuava: Unicentro, 2008. P. 79-1 I5, citando o depoimento de João Santos concedido a Marla Rupp.

36 E. S. P. Entrevista concedida a Ancelmo Schörner em 22 de setembro de 2009.

${ }^{37}$ TOLEDO, IIma Aparecida. Representações e práticas culturais no Sistema Faxinal. In: SOCHODOLAK, Hélio e CAMPIGOTO, José Adilçon. (Org.). Estudos em História Cultural na Região Sul do Paraná. Guarapuava: Unicentro, 2008. p. I I7-I 50, citando o depoimento de Amador 
Ferreira Lourenço concedido à autora.

38 E. S. P. Entrevista concedida a Ancelmo Schörner em 22 de setembro de 2009.

${ }^{39}$ CORRÊA, Roberto Lobato. Território e corporação: um exemplo. In. SANTOS, Milton, SOUZA, Maria Adélia Aparecida de e SILVEIRA, Maria Laura. (Org). Território, globalização e fragmentação. São Paulo: Hucitec, 1994.

${ }^{40}$ RAFESTIN, Claude. Por uma geografia do poder. São Paulo: Ática, 1993.

${ }^{41}$ GUATTARI, Félix; ROLNIK, Suely. Micropolítica: cartografias do desejo. Petrópolis: Vozes, 1996, p. 232.

${ }^{42}$ HAESBAERT, Rogério. Concepções de território para entender a desterritorialização. Território, Territórios, Programa de Pós-Graduação em Geografia da UFF, Niterós, 2002.

${ }^{43}$ SANTOS, Gislene Aparecida. Redes e território: reflexões sobre a migração. In: DIAS, Leila Christina e SILVEIRA, Rogério Leandro Lima da. (Org.). Redes, sociedades e territórios. 2 ed., Santa Cruz do Sul: Edunisc, 2007. p. 59.

${ }^{44}$ KOWARICK, Lúcio. Usos e abusos: reflexões sobre as metamorfoses do trabalho. In: HOGAN, Daniel. Cidade: usos e abusos. São Paulo: Brasiliense, 1978. p. 15.

${ }^{45}$ Enedina Rosa. Entrevista concedida a Ancelmo Schörner em 16 de setembro de 2009.

${ }^{46}$ J. P. L. Entrevista concedida a Ancelmo Schörner em 17 de setembro de 2009.

${ }^{47}$ Júlio Andrade. Entrevista concedida a Ancelmo Schörner em 16 de setembro de 2009.

${ }^{48}$ KOWARICK, Lúcio. Usos e abusos: reflexões sobre as metamorfoses do trabalho. In: HOGAN, Daniel. Cidade: usos e abusos. São Paulo: Brasiliense, 1978. p. 75.

${ }^{49}$ Enedina Rosa. Entrevista concedida a Ancelmo Schörner em 16 de setembro de 2009.

${ }^{50}$ BOSI, Ecléa. Cultura e desenraizamento. In: BOSI, Alfredo. Cultura Brasileira: temas e situações. São Paulo: Ática, 1992. p. 17.

${ }^{51}$ Enedina Rosa. Entrevista concedida a Ancelmo Schörner em 16 de setembro de 2009.

${ }^{52}$ DURHAM, Eunice. A caminho da cidade: a vida rural e a migração para São Paulo. São Paulo: Perspectiva, 1984, p. 8.

${ }^{53} \mathrm{BOSI}$, Ecléa. Cultura e desenraizamento. In: BOSI, Alfredo. Cultura Brasileira: temas e situações. São Paulo: Ática, 1992. p. 17.

${ }^{54}$ HAESBAERT, Rogério. Desterritorialização: entre as redes e os aglomerados de exclusão. In: CASTRO, Iná Elias de, GOMES, Paulo César da Costa; CORRÊA, Roberto Lobato (Org.). Geografia: 3 ed., Rio de Janeiro: Bertrand Brasil, 200 I p. 168, grifo no original.

${ }^{55}$ HAESBAERT, Rogério. Desterritorialização: entre as redes e os aglomerados de exclusão. In: CASTRO, Iná Elias de, GOMES, Paulo César da Costa e CORRÊA, Roberto Lobato. (Org.) Geografia: conceitos e temas. 3 ed., Rio de Janeiro: Bertrand Brasil, 200 I. p. 177.

${ }^{56}$ HAESBAERT, Rogério. O mito da desterritorialização e as 'regiões-rede'. Anais do $5^{\circ}$ Congresso Brasileiro de Geógrafos. Curitiba, AGB, 1994. 